\title{
A case of atlanto-occipital fusion with other multiple anatomic variations
}

\author{
H. Yang\#, J. Li\#, L. Liao, Y. Li \\ School of Traditional Chinese Medicine, Southern Medical University, Guangzhou, China
}

[Received: 7 June 2021; Accepted: 6 July 2021; Early publication date: 21 July 2021]

In the routine anatomic measurement study on Asian dry skulls, a skull of atlanto-occipital fusion with other multiple anatomic variations was observed. The entire right half of the atlas vertebra, including the anterior arch, anterior tubercle, posterior arch, and lateral masses, was fused entirely with the occipital bone, while the left fused partly. Besides the atlanto-occipital fusion, the target skull specimen also includes posterior arch defects of the atlas, metopic suture, and wormian bones. So many anatomical variations rarely exist in one specimen. This paper aims to present detailed anatomic case reports and discuss related diseases in an anatomic and clinical study. (Folia Morphol 2022; 81, 3: 804-808)

Key words: atlanto-occipital fusion, metopic suture, anatomic variations, skull

\section{INTRODUCTION}

The atlanto-occipital fusion (AOF) is also known as atlas occipital ossification, atlas assimilation, or atlas occipital fusion. It is a congenital osseous or fibrous anomaly caused by the partial or complete fusion of the atlas to the occipital bone [22]. The range of AOF involves any part of the atlanto-occipital joint, and most of the fusion is asymmetrical. According to the degree of atlas and occipital fusion, it can be divided into two types: complete atlanto-occipital segment insufficiency, that is, complete atlas fusion with the edge of the occipital foramen magnum; and partial atlanto-occipital segment insufficiency, which is often separated by atlas anterior arch fusion and posterior arch separation, one occipital condyle fuses with the superior articular surface of the atlas, but the other side is not fused [25].

The AOF was first described by Rokitansky in 1844 and demonstrated roentgenographically by Schuller in 1911 [see 3]. According to the report, the inci- dence of AOF ranges from $0.14 \%$ to $0.75 \%$ of the population [19]. As more profound research goes, it was found that the prevalence ranges from $0.08 \%$ to $2.79 \%$ of the general population; males and females were equally affected but may differ in races [31]. Individuals with AOF may have a low hairline, torticollis, restricted neck movements with or without abnormal short neck [20].

Vault consists of several curved plates separated by sutures rather than a single bone. The metopic suture (MS) is one of the primary sutures of the skull, which is located on the left and right sides of the frontal bone [28]. As people age, the cranial sutures fuse gradually, transforming the skull into a single, rigid element. The MS unites and disappears early in life, but there is no conclusion about the fusion time. Rice [24] thinks that the MS fusion starts at the age of one and completes before seven; according to other opinions it occurs at three years old; however, most authors believe it ends before 9 months $[29,30]$. The

Address for correspondence: Dr. Y. Li, School of Traditional Chinese Medicine, Southern Medical University, No. 1838, North of Guangzhou Great Road, BaiYun District, Guangzhou, Guangdong Province, 510515, China, tel: +86 13114466285, e-mail: 1065485398@qq.com; ortho@fimmu.com \#These authors contributed equally to this work. Han Yang is the first author, and Junhua Li is the co-first.

This article is available in open access under Creative Common Attribution-Non-Commercial-No Derivatives 4.0 International (CC BY-NC-ND 4.0) license, allowing to download articles and share them with others as long as they credit the authors and the publisher, but without permission to change them in any way or use them commercially. 

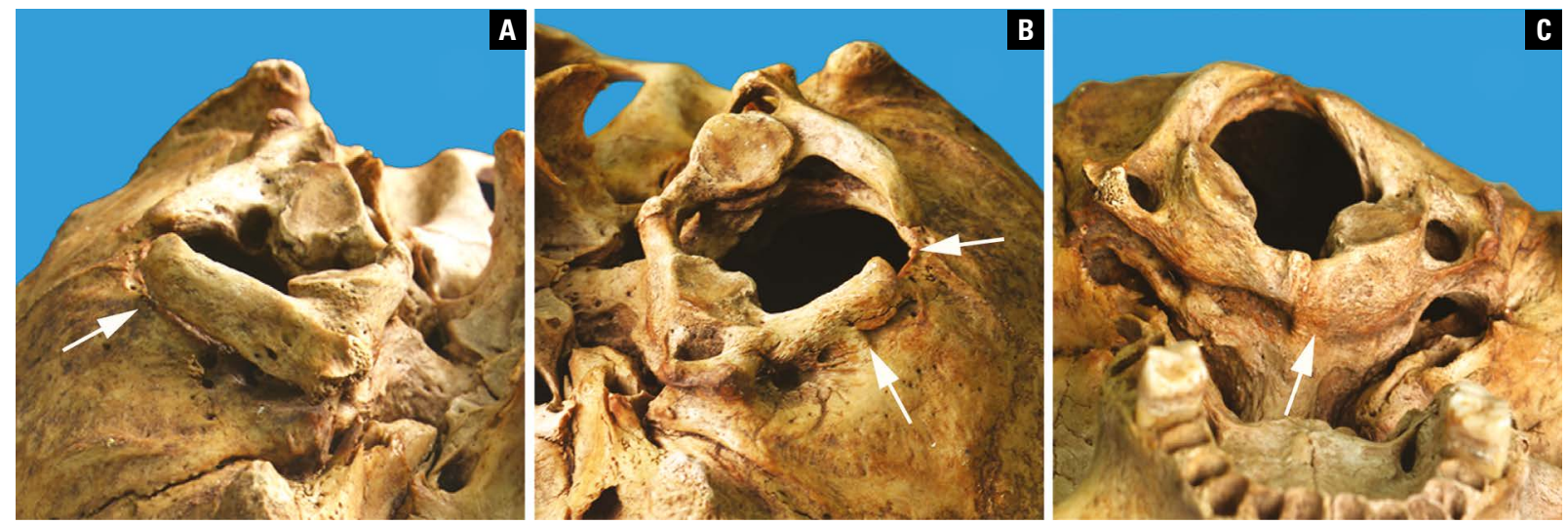

Figure 1. A. The left posterior arch was incompletely fused with the occipital bone (arrow); B. The posterior arch defects of the atlas, and the posterior tubercle was absent (arrow). The right posterior arch was fused entirely with the occipital bone (arrow); C. Partial fusion of the left anterior arch and anterior tubercle of the atlas with the occipital bone, and complete fusion of the right anterior arch and anterior tubercle with the occipital bone (arrow).

premature closure of MS will cause trigonocephaly and affect brain development in turn. It is still unclear why the closure of MS continues into adulthood. The existence of the MS in an adult cranium is described as a median frontal suture or a persistent metopic suture [11]. It is generally recognized as a normal variation. Studies have reported that the incidence of MS is $2.20-8.1 \%$. Meanwhile, racial and gender factors vary in MS $[7,11]$.

This report presents a rare case of AOF, posterior arch defects of the atlas (PADA), MS, wormian bones (WBs). The specimen was an adult male and belonged to the Southern Medical University, China.

\section{CASE REPORT}

In this specimen, the left anterior arch of the atlas and the anterior tuberosity were partially fused with the occipital bone, and the right anterior arch and the anterior tuberosity were completely fused with the occipital bone (Fig. 1).

The posterior arch of the atlas was deficient, and the posterior tubercle was absent. The right posterior arch was shorter $(29.9 \mathrm{~mm})$ and completely fused with the occipital bone (Fig. 1B). In comparison, the left posterior arch was longer $(36.2 \mathrm{~mm})$ and incompletely fused with the occipital bone (Fig. 1A). Findings indicate that the shape of the posterior cranial fossa is significantly associated with occipitalisation with and without cleft of the posterior arch of the atlas [8]. The fusion typically involves the anterior arch and foramen magnum; the posterior fusion involving lateral masses or the posterior arch is comparatively uncommon.
The distribution of the left and right mass of the atlas was asymmetrically fused with the occipital bone, the articular surface of the left mass was oval and small (transverse diameter: $17.9 \mathrm{~mm}$, vertical diameter: $15.8 \mathrm{~mm}$ ), and the articular surface of the right mass was irregular and large (transverse diameter: $20.1 \mathrm{~mm}$, vertical diameter: $17.4 \mathrm{~mm}$ ), which led to the irregularity of occipital foramen shape (sagittal diameter: $36.4 \mathrm{~mm}$, transverse diameter: $32.1 \mathrm{~mm}$ ) (Fig. 2B). The studies suggest a fusion between AOF and the dimensions of the foramen magnum that the sagittal dimensions and area of the foramen magnum were significantly smaller in skulls with occipitalisation [8]. Foramen magnum is an important landmark, which is closely associated with the brainstem and spinal cord [27]. AOF, reduced foramen magnum and basilar invagination may compress the medulla-spinal cord transition and the spinal cord or brain stem [15].

In addition, we found the disclosure of the MS in the skull of this case (Fig. 2A). The MS was complete, and the length from the bregma to the nasion was about $132 \mathrm{~mm}$ (Fig. 2C). In this case, there are multiple WBs in the lambdoid suture (Fig. 2D).

\section{DISCUSSION}

So many anatomical variations rarely exist in one specimen. An early defect in embryogenesis is postulated for such a combination, which may exemplify specific associations in which multiple embryological abnormalities were present.

The bony cranial base develops in the process of endochondral ossification, and a combination of 

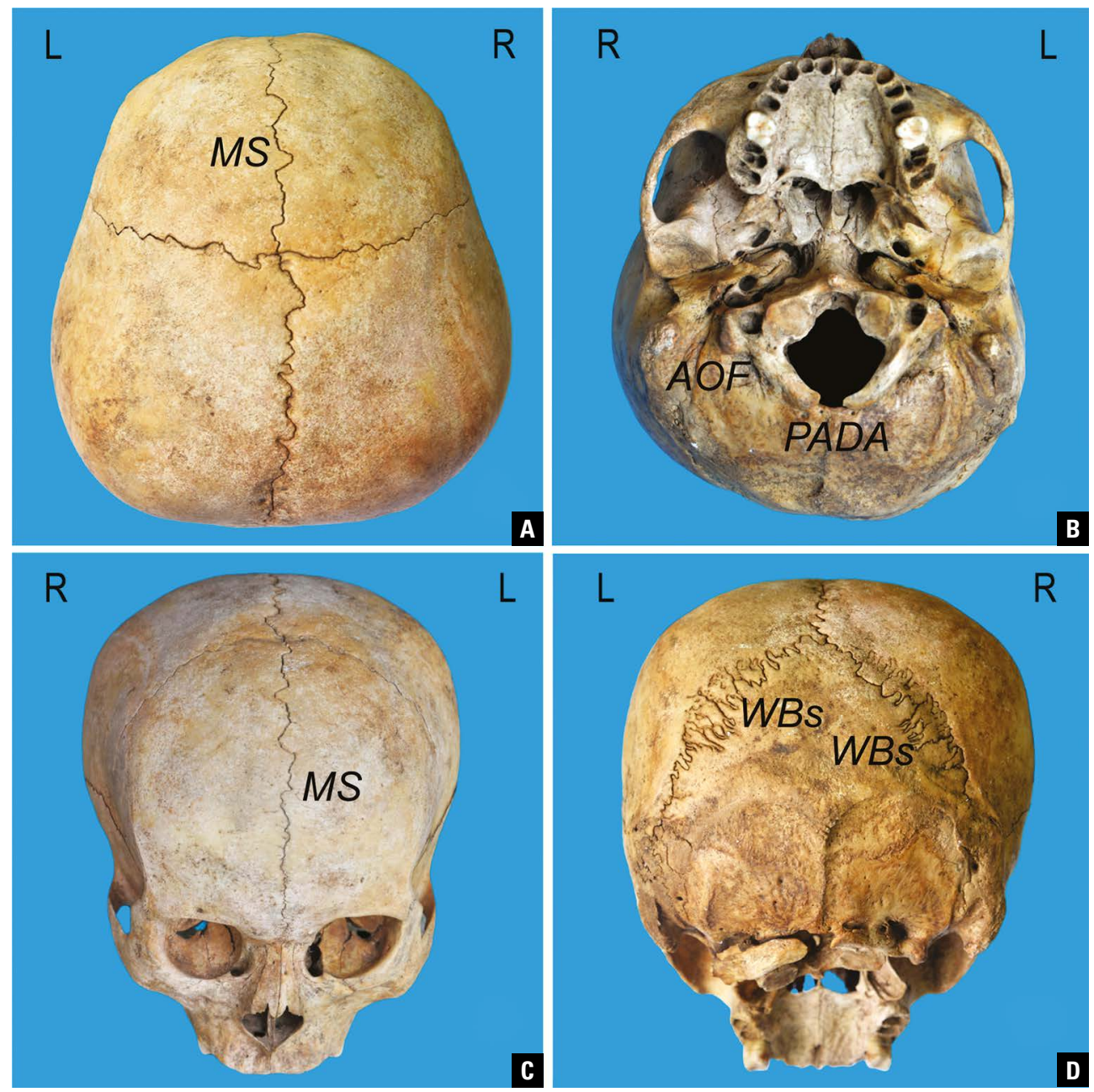

Figure 2. A. Metopic suture (MS); B. Atlanto-occipital fusion (AOF); posterior arch defects of the atlas (PADA); C. Metopic suture (MS); D. Wormian bones (WBs).

bony accretion and sutural growth is necessary for its development. The absence of both cartilaginous and bony components of the posterior elements implies a very early defect in embryogenesis $[17,23]$. AOF usually refers to the anatomic form of atlas and occipital bone not separated as scheduled during embryonic development. The congenital fusion of AOF includes a bony or fibrous fusion of part and all of the atlas anterior arch, posterior arch, and lateral mass with the occipital bone. And it is often accompanied by cervical 1-2 (C1-2) instability, cervical 2-3 (C2-3) fusion, basilar invagination, occipital dysplasia, Kleipper-Feil syndrome, and other diseases. It is a common congenital craniocervical junction malformation [13, $16,18,21]$.

As early as the $5^{\text {th }}-6^{\text {th }}$ week of the embryonic stage, the earliest vertebral body embryo is formed in the upper half of the next vertebral segment and the lower half of the upper vertebral segment. The atlas formation occurs primarily by the first spinal sclerotome, with a minor contribution from the proatlas [3]. In the vertebral chain of the human, the spine undergoes chondrification and ossification, and the $1^{\text {st }} 4^{\text {th }}$ occipital segments fuse with each other to form the base of the occipital bone. The head end of the $4^{\text {th }}$ occipital segment fuses with the $1^{\text {st }}$ cervical segment to form the atlas, and the acquired AOF is caused by incomplete segments [26]. AOF is usually congenital, but it may result from a disease such as osteomyelitis, arthritis, syphilis, or tuberculosis in rare cases.

The skeletal dysplasias are often associated with structural weakness and collapse of the skeleton [17]. Children affected by spondyloepiphyseal dysplasia, achondroplasia, and other forms of dwarfism have an increased incidence of craniovertebral 
abnormalities. There are various congenital, hereditary, developmental, and acquired abnormalities at the craniovertebral junction, either single or in combination. A significant number of children had both neural and osseous abnormalities [26]. Still, the studies indicate that occipitalisation is associated with the surrounding bony structures and not with the craniofacial morphology in general $[8,10]$. So we can't make a diagnosis just by the surface; detailed radiologic studies, possibly with volumetric reconstructions, are necessary in cases of AOF before surgical interventions in the region of craniovertebral junction [10].

The MS may reside as a partial pattern or a complete pattern. The partial patterns expand upward from the nasion or downward from the bregma, different from the completes spanning from the bregma to the nasion $[1,4,32]$. The suture forms from the bregma and develops toward the nasion. Inversely, the suture closes from the nasion toward the bregma [9]. Studies have shown that $91.66 \%$ of skulls with MS are associated with WBs [11].

The MS plays an important role in the shaping of the skull during the delivery of the baby. Because the baby has to be squeezed through the pelvis during delivery and due to many changes in bipedalism, the shape of the maternal pelvis is short and wide. In terms of modern women, the average sagittal plane of the entrance to the pelvis is $113 \mathrm{~mm}$, which is lower than $124 \mathrm{~mm}$ of the newborn's head. Therefore, cranial sutures such as MS can deal with strain by dissipating tension and shear force to help babies squeeze through the birth canal. The high incidence of up to $30 \%$ of parturition complications associated with MS has been confirmed [12]. Another study model the effect of brain growth on cranial bones by means of finite-element analysis and geometric morphometric techniques, further elucidated the relationship between cranial sutures and brain development [5].

Metopic suture may be confused with midline fractures of the frontal bone in radiology which is of clinical significance. In addition, studies have shown that MS is associated with other clinically significant findings, such as frontal sinus abnormality, cleft lip, visceral inversion, cleft palate, cretinism, and intelligence deficits $[2,6,14,32]$.

In addition, this paper also discusses the causes of this congenital malformation from the perspective of embryology. The knowledge of this uncommon anatomic variation is imperative for radiologists, neurologists, and neurosurgeons [3].

\section{CONCLUSIONS}

We reported a case of AOF with other multiple anatomic variations. So many anatomy variations rarely exist in one specimen. This paper presents detailed anatomic case reports and discusses related diseases in an anatomic and clinical study.

\section{Acknowledgements}

The authors sincerely thank those who donated their bodies to science to perform anatomical research. Results from such research can potentially increase humanity's overall knowledge that can then improve patient care. Therefore, these donors and their families deserve our highest gratitude.

\section{Conflict of interest: None declared}

\section{REFERENCES}

1. Aksu F, Cirpan S, Mas NG, et al. Anatomic features of metopic suture in adult dry skulls. J Craniofac Surg. 2014; 25(3): 1044-1046, doi: 10.1097/SCS.0000000000000564, indexed in Pubmed: 24699103.

2. Allanson JE, Cunniff C, Hoyme HE, et al. Elements of morphology: standard terminology for the head and face. Am J Med Genet A. 2009; 149A(1): 6-28, doi: 10.1002/ ajmg.a.32612, indexed in Pubmed: 19125436.

3. Al-Motabagani M, Surendra M. Total occipitalization of the atlas. Anat Sci Int. 2006; 81(3): 173-180, doi: 10.1111/j.1447-073x.2006.00129.x.

4. Bademci G, Kendi T, Agalar F. Persistent metopic suture can mimic the skull fractures in the emergency setting? Neurocirugia (Astur). 2007; 18(3): 238-240, indexed in Pubmed: 17622463.

5. Barbeito-Andrés J, Bonfili N, Nogué JM, et al. Modeling the effect of brain growth on cranial bones using finite-element analysis and geometric morphometrics. Surg Radiol Anat. 2020; 42(7): 741-748, doi: 10.1007/s00276-02002466-y, indexed in Pubmed: 32266441.

6. Bilgin S, KantarcI UH, Duymus M, et al. Association between frontal sinus development and persistent metopic suture. Folia Morphol. 2013; 72(4): 306-310, doi: 10.5603/ $\mathrm{fm} .2013 .0051$, indexed in Pubmed: 24402751.

7. Çalışkan S, Oğuz KK, Tunalı S, et al. Morphology of cranial sutures and radiologic evaluation of the variations of intersutural bones. Folia Morphol. 2018; 77(4): 730-735, doi: 10.5603/FM.a2018.0030, indexed in Pubmed: 29569704

8. Caspersen LM, Kjaer I, Sonnesen L. How does occipitalization influence the dimensions of the cranium? Orthod Craniofac Res. 2010; 13(3): 162-168, doi: 10.1111/j.1601-6343.2010.01492.x, indexed in Pubmed: 20618718. 
9. Chaoui R, Levaillant JM, Benoit B, et al. Three-dimensional sonographic description of abnormal metopic suture in second- and third-trimester fetuses. Ultrasound Obstet Gynecol. 2005; 26(7): 761-764, doi: 10.1002/uog.2650, indexed in Pubmed: 16308900.

10. Ciołkowski M, Krajewski P, Ciszek B. A case of atlas assimilation: description of bony and soft structures. Surg Radiol Anat. 2013; 36(8): 833-836, doi: 10.1007/ s00276-013-1235-9.

11. Cirpan S, Aksu F, Mas N, et al. Coexistence of wormian bones with metopism, and vice versa, in adult skulls. J Craniofac Surg. 2016; 27(2): 493-495, doi: 10.1097/ SCS.0000000000002370, indexed in Pubmed: 26845093.

12. Cornelissen MJ, Söfteland M, Apon I, et al. Perinatal complications in patients with unisutural craniosynostosis: An international multicentre retrospective cohort study. J Craniomaxillofac Surg. 2017; 45(11): 1809-1814, doi: 10.1016/j. jcms.2017.08.012, indexed in Pubmed: 28935489.

13. Dolenšek J, Cvetko E, Snoj Ž, et al. Complete occipitalization of the atlas with bilateral external auditory canal atresia. Surg Radiol Anat. 2017; 39(9): 1053-1059, doi: 10.1007/s00276-017-1826-y, indexed in Pubmed: 28214971.

14. Guerram A, Le Minor JM, Renger S, et al. Brief communication: The size of the human frontal sinuses in adults presenting complete persistence of the metopic suture. Am J Phys Anthropol. 2014; 154(4): 621-627, doi: 10.1002/ ajpa.22532, indexed in Pubmed: 24888448.

15. Honjo RS, Castro MA, Ferraciolli SF, et al. Cerebellofaciodental syndrome in an adult patient: Expanding the phenotypic and natural history characteristics. Am J Med Genet A. 2021; 185(5): 1561-1568, doi: 10.1002/ ajmg.a.62140, indexed in Pubmed: 33645901.

16. Kalla AK, Khanna S, Singh IP, et al. A genetic and anthropological study of atlanto-occipital fusion. Hum Genet. 1989; 81(2): 105-112, doi: 10.1007/BF00293884, indexed in Pubmed: 2912881.

17. Kumar R, Kalra SK, Vaid VK, et al. Craniovertebral junction anomaly with atlas assimilation and reducible atlantoaxial dislocation: a rare constellation of bony abnormalities. Pediatr Neurosurg. 2008; 44(5): 402-405, doi: 10.1159/000149909, indexed in Pubmed: 18703888.

18. Ma L, Song Y. A rare case of Klippel-Feil syndrome associated with atlantoaxial rotatory subluxation, atlanto-occipital fusion, and spina bifida. Spine J. 2015; 15(12): e57-e58, doi: 10.1016/j.spinee.2015.07.459, indexed in Pubmed: 26259886.

19. Macalister $A$. Notes on the development and variations of the atlas. J Anat Physiol. 1893; 27(Pt 4): 519-542, indexed in Pubmed: 17232056.

20. Mcrae DL, Barnum AS. Occipitalization of the atlas. Am J Roentgenol Radium Ther Nucl Med. 1953; 70(1): 23-46, indexed in Pubmed: 13058024.
21. Menezes AH. Craniocervical developmental anatomy and its implications. Childs Nerv Syst. 2008; 24(10): 1109-1122, doi: 10.1007/s00381-008-0600-1, indexed in Pubmed: 18401563.

22. Natsis K, Lyrtzis C, Totlis T, et al. A morphometric study of the atlas occipitalization and coexisted congenital anomalies of the vertebrae and posterior cranial fossa with neurological importance. Surg Radiol Anat. 2017; 39(1): 39-49, doi: 10.1007/s00276-016-1687-9, indexed in Pubmed: 27192980.

23. O'Rahilly R, Müller F, Meyer DB. The human vertebral column at the end of the embryonic period proper. 2 . The occipitocervical region. J Anat. 1983; 136(Pt 1): 181-195, indexed in Pubmed: 6833119.

24. Rice DP. Developmental anatomy of craniofacial sutures. Front Oral Biol. 2008; 12: 1-21, doi: 10.1159/000115028, indexed in Pubmed: 18391492.

25. Sharma DK, Sharma D, Sharma V. Atlantooccipital fusion: prevalence and its developmental and clinical correlation. J Clin Diagn Res. 2017; 11(6): AC01-AC03, doi: 10.7860/ JCDR/2017/26183.9999, indexed in Pubmed: 28764139.

26. Stratemeier $P H$, Jensen SR. Partial regressive occipital vertebra. Neuroradiology. 1980; 19(1): 47-49, doi: 10.1007/ BF00369089, indexed in Pubmed: 7354918.

27. Ulcay T, Kamaşak B, Görgülü Ö, et al. A golden ratio for foramen magnum: an anatomical pilot study. Folia Morphol. 2022; 81(1): 220-226, doi: 10.5603/FM.a2021.0018, indexed in Pubmed: 33634836.

28. Vinchon M. The metopic suture: Natural history. Neurochirurgie. 2019; 65(5): 239-245, doi: 10.1016/j.neuchi.2019.09.006, indexed in Pubmed: 31562880.

29. Vu HL, Panchal J, Parker EE, et al. The timing of physiologic closure of the metopic suture: a review of 159 patients using reconstructed 3D CT scans of the craniofacial region. J Craniofac Surg. 2001; 12(6): 527-532, doi: 10.1097/00001665-200111000-00005, indexed in Pubmed: 11711818.

30. Weinzweig J, Kirschner RE, Farley A, et al. Metopic synostosis: Defining the temporal sequence of normal suture fusion and differentiating it from synostosis on the basis of computed tomography images. Plast Reconstr Surg. 2003; 112(5): 1211-1218, doi: 10.1097/01. PRS.0000080729.28749.A3, indexed in Pubmed: 14504503

31. Yin Yh, Yu Xg, Zhou Db, et al. Three-dimensional configuration and morphometric analysis of the lateral atlantoaxial articulation in congenital anomaly with occipitalization of the atlas. Spine (Phila Pa 1976). 2012; 37(3): E170-E173, doi: 10.1097/BRS.0b013e318227efe7, indexed in Pubmed: 21681136.

32. Zdilla M, Russell M, Koons A, et al. Metopism: a Study of the Persistent Metopic Suture. J Craniofac Surg. 2018; 29(1): 204-208, doi: 10.1097/scs.0000000000004030. 